\title{
A volta da Cobra Canoa: em busca de uma antropologia indígena
}

DoI

http://dx.doi.org/10.11606/ 2179-0892.ra.2017.132068

\section{João Paulo Lima Barreto e Gilton Mendes dos Santos}

- Universidade Federal do Amazonas / Manaus, AM, Brasil

$\boldsymbol{\nabla}$ jplbarreto@gmail.com, giltonmendes@terra.com.br

RESUMO

Este texto, escrito a quatro mãos, trata do processo das Políticas Afirmativas no Programa de Pós-Graduação em Antropologia da Universidade Federal do Amazonas (UFAM). Ele descreve o enfrentamento dos desafios e o desenvolvimento de um exercício de reflexividade na busca de uma antropologia indígena.
PalavRas-chave

Políticas

Afirmativas; PPCAS/UFAM; reflexividade indígena; antropologia indígena. 
O Programa de Pós-Graduação em Antropologia Social (PPCAS) da Universidade Federal do Amazonas (UFAM) foi, se não pioneiro, um dos primeiros programas de antropologia no Brasil a conceder vagas reservadas para indígenas'. Implantada em 2010 (Mestrado) $^{2}$ e 2015 (Doutorado), o percentual reservado para indígenas (e agora também negros) é da ordem de $25 \%$ das vagas-doravante em caráter suplementar. Essa ação já acolheu, nesses anos, um total de vinte e cinco estudantes indígenas (dois destes ingressantes pelo processo regular), sendo dezesseis homens e nove mulheres. De diferentes procedências regionais e étnicas, esses estudantes são: Tukano (6), Tikuna (2), Wapixana (2), Waiwai (2), Macuxi (2), Piratapuia (2), Tariano (1), Kokama (2), Baré (2), Kambeba (1), Dessana (1), Tuyuka (1) e Bará (1).

Com pequenas alterações ao longo desse tempo, o Programa adota, através de edital, um processo diferenciado para a seleção de candidatos indígenas, pautado na exigência de uma proposta de pesquisa; um memorial, contendo informações sobre a trajetória de vida do candidato e sua formação acadêmica; a análise crítica de um item da bibliografia indicada; e a entrevista.

A despeito dessa conquista, no entanto, temos percebido cada vez mais a necessidade de avançarmos na consolidação de uma política integral, que considere não apenas a forma diferenciada de ingresso, mas de todo o processo de formação, que compreende, dentre outras coisas, a oferta de disciplinas, a dedicação do(a) orientador(a), a pesquisa de campo, a escrita e a defesa da monografia. A esse respeito, passaremos a publicar, a partir do próximo ano, um edital específico para os candidatos indígenas, que permite explicitar o processo diferenciado de seleção, explorando critérios mais apropriados. Com isso, pretendemos, também, escapar do "caráter de exceção", sempre presente nos editais de seleção, onde a política afirmativa aparece sob condição suplementar ou adventícia.

Uma conquista de monta no último ano foi a aprovação, no âmbito do colegiado do programa, do reconhecimento do direito do aluno indígena escrever sua dissertação ou tese em língua vernácula. Ainda que tenha suscitado críticas por parte de colegas de diversos cantos do Brasil, dizendo que a antropologia teria pouco a ganhar com isso, acredito que, desapegando de um egoísmo epistemológico, a antropologia deles é que tem a ganhar, uma vez que a produção elaborada pelos estudantes indígenas pode circular com mais fluidez e amplitude entre seus pares, em seus grupos e comunidades.

A experiência protagonizada pelo PPGAS/UFAM influenciou, paradoxalmente, a criação, pelo Conselho Superior da UFAM, da Resolução 010/2016, que trata da obrigatoriedade de implantação de políticas afirmativas em todos os Programas de Pós-Graduação da instituição, bem como do direito do aluno escrever a monografia em sua própria língua.

Tenho defendido a posição de que a criação de vagas reservadas para inmodificada e atualizada do artigo intitulado "Des Poissons et des hommes - Pour une autre anthropologie", publicado em Les Temps Modernes (Lima Barreto e Mendes dos Santos, 2015).

2 Em 2014, a Pró-Reitoria de Pesquisa e Pós-Graduação da UFAM impediu o processo de seleção do PPCAS para candidatos indígenas, alegando falta de regulamentação pela instituição - fato este que desencadeou uma série de protestos por parte de indígenas, professores e diversos pesquisadores e instituições no Brasil. Retomamos as vagas em 2015 , e agora em 2016 também para candidatos negros. 
dígenas está longe de uma benevolência do Estado ou ainda de um benefício exclusivo ao estudante, dando-Ihe a oportunidade de ingressar na pós-graduação. Acredito que o ingresso de indígenas na pós-graduação em antropologia faz bem, acima de tudo, para a própria disciplina, que passa a acolher no seu interior diferentes modos, discursivos e práticos, de conhecimento.

Por outro lado, não acredito que o simples ingresso dos índios (ou outras minorias) na universidade seja suficiente para assegurar al guma mudança: a entrada das pessoas não significa a entrada de suas ideias, de seus esquemas (outros) de praticar, viver e pensar o mundo e a vida. Também não acredito que existe um lugar na esfera epistêmica, transcultural, aguardando um encontro entre os diferentes saberes, científicos e não científicos, conforme defende Ramos (2014).

Quando chega à universidade, num curso de graduação ou de pós-graduação (em antropologia ou qualquer outra área), o estudante indígena já está com a "cabeça feita", com as verdades (científicas) cristalizadas, conquistadas à duras penas na escola - aliás, foi exatamente isso o que o permitiu chegar aí. Essas verdades apreendidas, no entanto, não parecem ser aquilo que o estudante indígena tem de melhor para nos legar, não parece ser o que ele traz de mais interessante. Se acreditamos na diferença entre o nosso modo de pensar com aqueles outros modos, então esperamos encontrar categorias diferentes das nossas. Mas, como encontrar essa diferença, tendo em mente a realidade de um longo processo de aprendizado de verdades científicas que os indígenas foram e são submetidos desde a infância, nas escolas, das aldeias e das cidades?! Este me parece ser um dos maiores desafios: rachar as palavras, quebrar as verdades, rasgar as caixinhas da ciência, desconstruir o construído, e em seu lugar erguer, sobre os escombros da destruição, novos edifícios de verdades, novos conceitos e categorias.

Portanto, não basta desconstruir as verdades conquistadas, aprendidas, é preciso (re)construir novas verdades, identificar e sistematizar categorias e conceitos, agora, a partir de um exercício de reflexividade, para usar um termo de Carneiro da Cunha (2010). Assim, espera-se mais (e muito) dos estudantes indígenas, uma diferença pensada e verbalizada por eles próprios. Esse exercício de reflexividade me parece um caminho possível para se começar, de fato, um processo de revelações, de novidades e diferenças; de descolonização do pensamento.

Se oportunizarmos isso em nossos cursos e programas, quem sabe estaremos contribuindo de alguma forma para aquilo que cognominamos de epistemologia indígena. No entanto, fazer isso requer mudanças aqui também, no nosso modus operandi. Exige transformação de postura, de práticas e de concepções: é preciso pensar diferentemente do que se pensa e fazer diferentemente do que se faz. 
Após a promulgação da Constituição de 1988, o movimento indígena do Norte do Brasil, começou a formalizar suas instâncias de representação criando associações, federações e coordenações aos moldes de sociedade civil, visando enfrentar desafios de forma conjunta frente ao Estado. No início, a bandeira principal era a demarcação de terras, e logo se ampliou para outras áreas, como educação, saúde e geração de renda. Tais reivindicações fundamentavam-se na obtenção de proteção especial, sem ferir o princípio da organização social e de autonomia dos povos, perante fatores que ameaçavam a reprodução física e cultural dos povos.

Durante a formalização das organizações, suas lideranças foram percebendo que, além de lutar pela demarcação de terras, era necessário formar profissionais indígenas capazes de operacionalizar com a burocracia e as representações estatais. O caminho encontrado para isso foi o investimento na formação de jovens indígenas, na medida em que, muitas vezes os assessores não indígenas, e mais ainda os funcionários do Estado, não conseguiam entender a linguagem nativa.

Ciente desse desafio, na década de noventa, a Federação das Organizações Indígenas do Rio Negro (FOIRN) encaminhou uma carta à Reitoria da Universidade Federal do Amazonas (UFAM), reivindicando acesso diferenciado de alunos indígenas à Universidade. Ao mesmo tempo, a Federação das Organizações de Caciques e Comunidades Tikuna (FOCCT) tomou a mesma inciativa. Sem sucesso na empreitada, essas federações se juntaram em torno da Coordenação das Organizações Indígenas da Amazônia Brasileira (COIAB), fortalecendo assim a pressão sobre a Universidade. Como resultado, a UFAM ofertou um Curso Sequencial para a formação de lideranças indígenas, porém sem reconhecimento acadêmico oficial (diploma ou certificado).

Insatisfeitas com o curso, as organizações passaram a reivindicar o sistema de cotas, ampliando a luta em nível nacional. Como resultado dessa pressão, algumas universidades passaram a ofertar vagas para indígenas, de modo que hoje existe universidades públicas e privadas implementando as chamadas Políticas Afirmativas. Portanto, é importante enfatizar que o sistema de cotas criado pelas universidades é fruto de uma proposta e reivindicação sistemática e longa dos povos e comunidades, e não um gesto espontâneo, democrático e bondoso do Estado.

Passado esse tempo e essa fase, a luta agora é encarar o pensamento indígena, não basta entrar na Universidade, é preciso mostrar a diferença. Para tanto, é preciso descolonizar o pensamento, refletir sobre os conceitos científicos naturalizados pelos indígenas ao longo da história.

Minha entrada no curso de antropologia da UFAM não foi por opção profissional, mas por um ideal de um caminho possível de construção de conhecimen- 
to indígena para um diálogo com a ciência. Tanto que, quando fui convidado pelo professor Gilton Mendes para entrar no PPCAS, através das Políticas Afirmativas, no início não fiquei muito empolgado. A razão pelo desencanto com a antropologia era porque, a meu ver, essa área de conhecimento não trazia nenhuma novidade, nenhuma mudança sobre ou para os conhecimentos indígenas. Estava convencido de que seria mais um antropólogo, a exemplo de muitos outros colegas indígenas, que hoje são professores, gestores de escolas públicas, servidores públicos.

Fui vencido quando tive contato com a discussão da tal antropologia cruzada ou simétrica durante os seminários promovidos pelo Núcleo de Estudos da Amazônia Indígena (NEAI), pelas ideias do antropólogo Roy Wagner, e quando li o texto chamado Ciência da Floresta (Mendes dos Santos e Dias Júnior, 2009).

A partir dessa discussão, senti-me estimulado e fui levando à sério a ideia de elaborar um projeto para ingressar no mestrado em antropologia. Assim, elaborei um projeto intitulado "Um olhar indígena (tukano) sobre a ciência: uma etnografia no laboratório de pesquisa de ictiologia no Instituto Nacional de Pesquisas da Amazônia (INPA)".

No ano de 2011, beneficiados pela Política Afirmativa, eu e mais três colegas indígenas ingressamos no mestrado. Pouco tempo depois criamos o Colegiado Indígena, uma instância de interlocução entre o colegiado do Programa e os alunos indígenas. Logo vimos que implementar as chamadas Políticas Afirmativas significava apostar na existência de uma diferença de fato entre os modelos de conhecimentos, longe da ótica de justiça social. Significava que nós, indígenas, seríamos capazes de estudar nossos conhecimentos para além de narradores de mitos ou informantes e coadjuvantes de antropólogos, de modo a dialogar com a ciência a partir de categorias e conceitos que aproximam e distanciam os modelos de conhecimentos. Com essa ideia ingressei no mestrado.

Durante a pesquisa de campo tive várias crises, a mais intrigante foi quando percebi que fazer um estudo da ciência implicava lançar mão de uma etnografia do laboratório para promover um debate com os autores, o que não era meu objetivo (Lima Barreto, 2013). Diante do desafio, senti a necessidade de, minimamente, sistematizar os conhecimentos tukano, na medida em que as transcrições mitológicas e o que eu conhecia da produção indígena não davam conta de expressar as ideias indígenas e nem apresentavam um suporte teórico nativo.

Mesmo cheio de vontade para sistematizar os conhecimentos tukano nos moldes antropológicos, ainda tinha um problema pela frente, meu pouco domínio da cosmologia tukano. Assim, ciente dessa carência, decidi convidar meu pai para morar comigo em Manaus, com o intuito de ser meu interlocutor e orientador.

Dado esse passo, o laboratório de ictiologia passou a servir apenas como 
um estimulo para pensar o pensamento tukano. Conversando longas horas com meu pai, a partir de dados coletados no laboratório, e num exercício de reflexividade conjunto, íamos construindo certas noções e categorias tukano.

Assim, meu trabalho de mestrado, isto é, a elaboração da dissertação, deu-se a partir de uma triangulação de personagens: o laboratório, meu pai e meu orientador, que me proporcionavam questões e perspectivas diferentes. $O$ resultado desse exercício de reflexividade foi a descoberta de um equívoco na tradução e compreensão das categorias de wai-mahsã (super humanos) e wai (peixe). Como registrei em minha dissertação:

A categoria wai (peixe) foi motivo de uma confusão generalizada no Rio Negro, pois o termo wai-mahsã, traduzido ao pé da letra é: wai: peixe; mahsã: gente, pessoas. Assim, wai-mahsã seria entendido como "peixe-gente". Todavia, na cosmologia tukano, peixe não é gente, é uma categoria que se presta como veículo especial da comunicação entre humanos e wai-mahsã residentes e donos das habitações aquáticas (bahsakawi). (Lima Barreto, 2013: 14)

Esses dois termos e conceitos causaram uma enorme confusão, fazendo conferir, diretamente, uma associação entre uma coisa e outra, isto é, que os peixes possuem as mesmas capacidades dos humanos. Enfim, no meu trabalho eu tento explicar isso melhor, mas vale dizer que os seres chamados wai-mahsã (sempre grafado assim, separadamente) apresentam natureza diversa e tomam seus nomes emprestados de todos os animais, de todos os peixes, mas que não significam que são os próprios animais e peixes. Hoje temos escrito este termo sem o hífen, waimahsã, para melhor expressar seu sentido original.

João Paulo Lima Barreto

Conheci João Paulo Lima Barreto num momento em que me encontrava bastante motivado pela proposta da antropologia simétrica, anunciada por Bruno Latour (1994) e desenvolvida no Brasil por Eduardo Viveiros de Castro (1996; 2010). No ano anterior, havia escrito um texto, em coautoria com um colega, sobre o que cognominamos de antropologia cruzada (citado acima por João Paulo). Esse texto expressa o desejo de explorar uma "antropologia indígena", já que estávamos na Amazônia com um programa de pós-graduação em condições de envolver os indígenas na prática e na produção antropológicas. Ele argumenta ainda em favor de uma "epistemologia do conhecimento indígena", de um exercício feito pelos próprios índios; isto é, se a antropologia nos instrumentaliza a captar e conferir sentido aos fatos nos diferentes contextos culturais - de outras sociedades e de nossa própria -é de se apostar que os reconhecidos detentores dos 
conhecimentos indígenas estarão, assim, procedendo de igual maneira, tendo a nos dizer algo, com base nos seus princípios epistemológicos, não apenas sobre si, mas sobre nós, num efeito de "antropologia cruzada".

Encontrar com João Paulo nesse momento me pareceu muito oportuno para colocar em experimento aquilo que pensava de modo mais ambicioso e coletivo nas oficinas de saberes. Ter o interesse de um indígena tukano, recém-formado em filosofia, crítico à prática antropológica do (seu) outro, e disposto a fazer uma antropologia desse outro me pareceu um encontro encomendado.

Seu projeto, conforme ele já assinalou, tinha como pano de fundo realizar uma antropologia cruzada, isto é, observar um meio de produção do conhecimento científico a partir da prática com o peixe em laboratório, projetando-a num contexto de concepções e práticas indígenas (tukano) com o peixe. Aqui se apresentava o intento de uma "antropologia reversa" ou "cruzada", de ol har para os procedimentos da ciência com os óculos da cosmologia indígena e de explicar, nos termos e sentidos do entendimento indígena, o que se passava no laboratório, não apenas etnografando o que estava sendo observado, mas lendo-o em outra clave.

A escolha do peixe e das pesquisas em ictiologia, por sua vez, não foi por acaso. Na cosmologia tukano, o peixe ocupa um lugar de destaque, sendo fonte de explicação da gênese humana e dos diferentes coletivos étnicos habitantes do Alto Rio Negro, além de atuar como agente patogênico em situações liminares da vida social cotidiana.

Assim, passados alguns meses, já bastante curioso com o trabalho de João Paulo, flagrei-me bombardeando-o com inúmeras perguntas sobre o que ele estava notando em seu campo de pesquisa e como suas observações poderiam ser explicadas à luz da onto-cosmológica tukano. Para minha surpresa, comecei a notar que meu orientando reproduzia em discurso aquilo que observava como um tipo de conhecimento que ele passava a adquirir sobre os peixes. Isso me deixou, de certa forma, intrigado. Notei, ademais, certo incômodo por parte dele com minhas insistentes questões, que exigiam a revelação de um olhar indígena sobre aquilo que estava sendo feito no INPA. Não tardou para João Paulo admitir que de fato não estava conseguindo fazer uma leitura distanciada e crítica dos conhecimentos e procedimentos científicos observados, e mais, contrariamente ao que se supunha, se convencera de que não portava um cabedal de conhecimentos suficiente para acioná-lo numa compreensão sobre os peixes e seu lugar na própria cosmologia indígena. Seu domínio das "teorias tukano" era fragmentado e disperso, nunca antes colocado à prova como naquele momento. Seu entendimento das concepções práticas e discursivas tukano não encontrava profundidade satisfatória para ser acionado diante do que estava observando.

Desse modo, o projeto inicial de uma antropologia cruzada estava compro- 
metido, e uma decisão radical precisava ser tomada naquele momento, investir numa reflexividade da cosmologia tukano, numa busca e análise antropológica das formas de compreensão indígena sobre o cosmos e o lugar do peixe nessa cosmologia. Era preciso redirecionar o tempo gasto com a observação do campo científico, deixar imediatamente o laboratório e voltar-se para os domínios de conhecimento tukano.

Certo dia, para minha surpresa, João Paulo me deu a notícia de que seu pai estava baixando do al to Rio Negro para morar com ele em Manaus até a conclusão de sua pesquisa. Contente, ele me disse que agora contava com sua biblioteca particular, sua fonte e seu interlocutor. Assim, fiquei convencido de que ele estava disposto a dar cabo, minimamente, ao que precisava ser feito.

A decisão de João Paulo de ter trazido o pai, Ovídio Barreto, para junto dele revelou a prática de um novo método ou de uma nova maneira do método antropológico. Seu pai não foi apenas um informante, mas um interlocutor permanente, um companheiro de diálogo e de investigação conjunta. Eles se entendiam a partir de uma mesma referência cosmológica, como pertencentes de uma mesma tradição. Essa parceria evidenciou ainda a diferença e o lugar de cada um deles no processo de produção do saber. Ovídio figurava como um especialista (kumu), detentor e representante dos conhecimentos tukano, enquanto João Paulo faria uma tradução, não só de linguagem, mas de sentido, de idioma cultural, das coisas ditas pelo pai. Seu papel estava ali sendo definido, num entendimento de ambos, na medida em que ele se esforçava por encadear certas ideias, extrair conceitos e sentidos que pudessem ser demonstrados na linguagem escrita, científica e (antropo)lógica.

Enfim, o que estava em jogo naquele instigante e difícil processo de tradução, filtragens e escolhas era pensar sobre os conhecimentos indígenas, à maneira mesmo do ofício antropológico, mas com a diferença que ali estavam dois "nativos", dois indígenas, num jogo de espelhos, e que o diálogo entre eles certamente não teria o mesmo rendimento que aquele entre um indígena informante e um estrangeiro, um outro, um antropólogo de fora da tradição indígena.

O resultado da interação entre João Paulo e seu pai mostrava ainda que a natureza dos conhecimentos, ou melhor, os modos de expressão dos conhecimentos (antropológico e indígena), pertenciam e se faziam inteligíveis a domínios e contextos distintos. Complementarmente, João Paulo passou a conferir maior valor ao pai, vendo-o como alguém que possibilitava estabelecer um diálogo com a antropologia.

No entanto, como é de se esperar, tal exercício de reflexividade, que propõe traduzir os próprios conhecimentos ou a própria tradição, requer, antes de tudo, buscar outros termos e outras categorias. Isto é, encontra-se em jogo aqui uma segunda desconstrução: fazer a viagem de volta, colocando em cheque as verda- 
des até então conquistadas pela experiência científica, culminada na antropologia. Era preciso, no limite, descolonizar o pensamento, produzir uma segunda desconstrução: da referência comum indígena ao científico e deste ao indígena pensado, nos termos antropológicos.

A partir de certo momento, na condição de orientador acadêmico, passei a ver João Paulo como um antropólogo vê seu "observado", atento ao que ele dizia e fazia. Interessou-me, sobremaneira, perceber e analisar a relação que ele imprimia com os diferentes atores em jogo, com a antropologia que ele estudava, com os conhecimentos antropológicos produzidos sobre seu povo, com os trabalhos elaborados por outros estudantes indígenas, sua relação com o pai e também comigo como seu orientador e observador.

Ainda no transcorrer desse tempo me senti profundamente envolto e interessado pela cosmologia e sistemas de conhecimento tukano. Comecei a aprender com João Paulo. Devo a ele quase tudo o que sei sobre os Tukano do alto Rio Negro, lembrando que não sou um etnólogo especialista no grupo ou nessa região etnográfica.

Assim, em muitos momentos da trajetória do trabalho antropológico que imprimimos em conjunto, operou-se uma inversão de papéis, ora sendo eu seu orientador, ora seu aprendiz. Se isso, por si só, não define uma simetria da relação, pelo menos possibilita um movimento circular no processo de aprendizado, lição que tomei nessa experiência de orientador de um estudante indígena interessado em fazer aparecer seus conhecimentos, e reposicioná-los frente a seus pares.

Como disse João Paulo, o seu trabalho, a sua pesquisa, levou-o a uma descoberta aparentemente simples, mas fundamental para o entendimento antropológico das concepções tukano sobre a relação entre humanos e não humanos. A tradução das narrativas míticas do al to Rio Negro tem feito uma associação direta entre os peixes e a gênese humana, uma vez que, de fato, elas encontram-se muito imbricadas. Seguindo certos pressupostos da ontologia ameríndia, de que os animais possuem status de pessoa, isto é, qualidades antropocêntricas e atributos sociais semelhantes aos dos humanos, o ponto de partida da pesquisa de João Paulo foi a máxima de que "peixe é gente". O resultado, no entanto, do aprofundamento de seu diálogo com o pai, como vimos, revelou-se com uma surpresa: havia um problema no entendimento (inclusive em seu próprio, até aquele momento da pesquisa) sobre a relação entre a gênese humana, os peixes e os waimahsã.

A operação realizada e demonstrada em detalhe em seu trabalho foi escapar de uma análise historicamente focada no peixe enquanto sujeito bipolar, peixe-gente, incluindo aí um terceiro elemento, o waimahsã, muitas vezes justaposto na relação polar ou com importância minimizada na maioria dos estudos da cosmologia tukano. 
Depois de ter concluído o mestrado, continuei no NEAI/UFAM, participando do projeto de pesquisa chamado Rios e Redes na Amazônia. Durante três anos, essa pesquisa consistiu em promover um exercício coletivo sobre os conhecimentos tukano, a partir de um diálogo com os nossos especialistas, os kumuã.

A rigor, as equipes de pesquisadores indígenas e não indígenas se debruçaram nos estudos etnográficos, num esforço de traduzir os conceitos tukano e as articulações cosmopolíticas. Os especialistas, acostumados a narrar longas mitologias, entraram no bojo desse exercício-especialmente quando realizamos o Simpósio de Kumuã na cidade de São Gabriel da Cachoeira em agosto de 2015. Do esforço coletivo foi possível concluir que os conhecimentos tukano ancoram-se em num tripé conceitual: kihti-ukuse (o conjunto das narrativas míticas), bahsese (ações cosmopolíticas - vulgarmente chamadas de benzimentos) e bahsamori (o conjunto das práticas rituais).

Durante esses anos, tive oportunidade de amadurecer minha proposta de pesquisa para continuar estudando, uma coisa que queria muito. No de ano de 2016 comecei meu doutorado, com a proposta de, agora sim, fazer um exercício de antropologia cruzada, estudando o hospital, sob a ótica tukano, como um lugar de desequilíbrio do cosmos.

A proposta é pensar esse equilíbrio/desequilíbrio a partir das "teorias tukano", partindo da investigação do que acontece no hospital. Não se trata de uma antropologia da saúde, mas sim de pensar um espaço e uma prática da saúde coletiva biológica sob uma perspectiva (epistemo)lógica tukano.

O hospital é um lugar onde a pessoa vai para resolver seus problemas (biológicos) individuais. Lá ela é submetida ao ritual da ficha, da fila, do credenciamento, da consulta, da hospitalização, da receita médica, do medicamento, dos enfermeiros, da cirurgia, da alimentação etc. Entretanto, para alguém que observa esse lugar com outro olhar, isto é, do ponto de vista indígena (tukano, no meu caso), tudo o que acontece ali é visto como a manifestação de seres do cosmos, onde os conflitos convergem, fruto da má relação dos humanos com seus pares, e com o ambiente.

Assim, vislumbro que o hospital é um bom lugar para pensar, para entender o cosmos como um todo, a partir da lógica tukano, que conecta o indivíduo numa teia de relações com outros seres, com os waimahsã, os animais, os especialistas, o ambiente, com as pessoas, seus parentes. Enfim, estou apenas iniciando meu doutorado, mas o que pretendo fazer é uma leitura do hospital pensando no mundo, como um lugar de desequilíbrio, de tensão, de perigo, de conflitos, de desarmonia, enfim, um lugar de expressão da desestruturação cósmica. Fazendo este trabalho, pretendo sair do entendimento restrito de que a doença é uma manifestação biológica individual.

Nem tudo, porém, é muito tranquilo quando entramos em diálogo com 
nossos especialistas, os kumuã. A política de produção de conhecimentos, que privilegia o registro via o entendimento da ciência e pela escrita, está sob forte crítica pelos "parentes", por ser um modelo que não traduz a forma e a dimensão como ela é concebida por eles. O método de anotar nas planilhas, construir tabelas e fazer estatísticas nos moldes científicos pouco apreende os conhecimentos, a filosofia e os conceitos indígenas. Como bem disse Higino Tenório Tuyuka: "anotar, medir ou escrever no papel é congelar, cristalizar e matar a alma dos nossos conhecimentos". Essa afirmação faz-nos pensar e avaliar a nossa forma de produção indígena, sobre nossos saberes no ambiente da universidade. A denúncia de Higino é no sentido de que o processo de adquirir, gerar e transmitir conhecimentos indígenas é completamente outro, não via a escola, a ciência, a lógica ocidental com seus conceitos e categorias. A formação indígena se dá por outras vias, por outros espaços, calcada em outra cosmologia.

Dessa forma, os especialistas indígenas estão em contínua operação intelectual, refletem sobre as mudanças de épocas, sobre as mudanças sociais, falam e fazem circular saberes - e a presença indígena nas universidades não passa batido. Usando tabaco e ipadu, eles fazem florescer novos saberes.

Como membro dessa sociedade, eu devo concordar com as análises e preocupações dos nossos especialistas. De fato, a formação clássica de yai, kumu e baya dos Tukano, a exemplo de outros grupos indígenas amazônicos, passa, antes de qualquer coisa, pelo investimento no corpo: o aprendiz é antes submetido à limpeza estomacal, com a ingestão de plantas, ao uso do kahpi (ayawaska) e wihõ (rapé) para os primeiros contatos com os waimahsã, à abstinência sexual e alimentar, à ingestão de pimenta, o isolamento da vida social etc. Os canais de aprendizagem, também, perpassam pela via de sonhos, pelos ritos de passagens e pelas longas horas de conversas e treinamento. O especialista, por fim, é aquele que domina as narrativas míticas e pratica seus conhecimentos por meios do kihti ukusse, do bahsessé e do bahsamori, colocando-os em ação no processo de cura, de assepsia dos alimentos e proteção dos lugares e das pessoas contra os ataques dos waimahsã.

Minha formação, como estudante indígena de antropologia, se dá de outra maneira e por outras vias. Na universidade, sei muito bem que serei um papera kumu, uma pessoa que sabe ler, escrever, falar português e comunicar com os "brancos". Entretanto, acredito que existe um campo intermediário nessa relação entre os especialistas e os jovens indígenas universitários, uma ponte que precisamos compreender e explorar.

Durante minha pesquisa de mestrado, eu percebi que os especialistas tukano com quem tive contato, compreendiam o que eu estava fazendo, e colaboravam comigo compartilhando a partir de suas experiências, falando no "idioma da cultura tukano", no jeito de funcionamento dos "conhecimentos tradicionais". 
Meu pai, por exemplo, conversava comigo numa perspectiva de transmissão, tal como se faz na aldeia, repassando os conhecimentos numa lógica outra, na forma de longas, completas e complexas narrativas. E eu, da minha parte, deveria fazer uma filtragem de tudo isso, traduzindo para uma lógica científica, antropológica e da escrita.

Como pessoa tukano, eu tinha a vantagem de traduzir tudo isso em termos mais a proximados da epistemologia indígena - embora não seja uma tarefa fácil, que peno até hoje. Isso exigiu e exige muita atenção para não cairmos nas armadilhas dos conceitos abstratos que a ciência ou o pensamento ocidental nos deixou de herança. Falo de noções como de indivíduo, de natureza, de cultura, de sociedade, de hierarquia, de poder, de espírito... Conceitos como o de reino animal, reino vegetal, mineral, e por aí vai.

Para explorar melhor nossos conhecimentos, precisamos minimamente nos afastar dos conceitos europeus ocidentais (aliás, aqui confesso minha limitação, nem sei como classificar isso) e mergulhar nos "conceitos nativos". Acredito que, ainda que seja pela escrita, pela ciência, é possível buscar os melhores termos, as melhores categorias, nos livrando de muitas das armadilhas conceituais. Acredito que é necessário pensar o pensamento.

Dessa forma, o que nós indígenas estamos fazendo dentro das universidades é outra coisa mesmo, outro tipo de conhecimento que não se aprende no contexto do universo tradicional, dos kumuã. Mas que também, por outro lado, não se pode limitar ao rebatimento direto nos conceitos científicos, ao reducionismo cientifico, de modo simplório e similar das lógicas e categorias (verdades) dadas.

Olhando de forma crítica, vejo a Universidade como aparelho do Estado que serve para integrar os indígenas. Ao longo da história, o Estado sempre manteve a filosofia de extirpar a condição indígena. Assim, ser índio correspondia a um estado transitório, que desapareceria na medida em que os grupos fossem gradativamente incorporados à sociedade nacional.

Superamos essa política integracionista? Creio que não. O que mudou foi a forma de olhar os indígenas, isto é, os índios são aqueles que sabem conviver com a natureza sem depredá-la, que têm seus mitos para explicar a origem do mundo, do homem, das coisas e das relações entre humanos e não-humanos. Entretanto, no campo intelectual, a relação continua assimétrica, de modo que os indígenas sempre estão na condição de "tábua rasa”: ensinar os índios é uma necessidade.

A instituição de políticas de acesso diferenciado dominante nas universidades, sob a ótica da benevolência do Estado e da justiça social, é um bom exemplo, pois ela supõe que as diferenças epistemológicas acabam quando os alunos indígenas conquistam o acesso à universidade. $\mathrm{O}$ sujeito indígena perde suas 
referências cosmológicas, perde o seu jeito de ser e pensar. A verdadeira orientação não é mais a dele, dos pais, ou de seus pares, mas a da ciência. Essa não é uma política de integração intelectual?

Nos últimos anos, o modelo de produção e reprodução de conhecimentos, implementado pelo sistema de ensino convencional, que tem como proposta registrar os conhecimentos via a escrita, fez confundir ainda mais os indígenas, fez-nos acreditar no tal do ensino-pesquisa. Nós, indígenas, temos que ter muito cuidado com o que aprendemos nas escolas e, sobretudo, nas universidades, com seus conceitos já prontos, buscando mentes para absorvê-los.

O que isso implica? Implica que, quando realizamos estudos e pesquisas sobre nossa(s) cultura(s), usando esses conceitos que aprendemos, tomando essas referências de modo ingênuo, caímos nas armadilhas conceituais ao traduzir nossos saberes, nossos conhecimentos, nosso pensamento e nossa lógica indígena de ser e de conceber as coisas. Significa dizer que, ao fazer a tradução e interpretação à luz desses conceitos, distanciamo-nos ainda mais das nossas epistemologias indígenas. Por exemplo, quando se trata de etnomatemática, somos levados a acreditar que dentro do conhecimento indígena também existe a noção de matemática, manifesta nas técnicas de tecer um cesto, de fazer um abano, de fabricar um urutu, que a quantidade de talas ou fibras que usamos para confeccionar estes instrumentos está no campo da matemática. Tudo isso, na verdade, pode ser traduzido sob outras categorias, mais justas e apropriadas ao entendimento indígena.

Quero concluir afirmando que o sistema de conhecimento tradicionalmente operante no al to Rio Negro, a transmissão e o acesso aos conhecimentos, sempre esteve relacionado com a trajetória de pamuri-yukusu, a conhecida Canoa da Transformação ou Cobra Canoa. Ao longo de sua viagem, que parte do Oceano Atlântico, atual cidade do Rio de Janeiro, até a Cachoeira de Ipanoré, no alto Rio Negro, existem muitos lugares onde ela parou, lugares que são chamados de pamuri-wiseri (casas de conhecimentos), isto é, residências de waimahsã do universo aquático, guardiões dos conhecimentos, com os quais os especialistas interagem e acessam tais conhecimentos. Uma possível antropologia indígena significa um exercício de reflexividade sobre esses conhecimentos originários de pamuri-wiseri. Fazer esse exercício através da antropologia tem sido para mim uma viagem de volta a esses lugares, a essas casas, enredado no sentido da Cobra Canoa. 
João Paulo Lima Barreto é indígena tukano, doutorando em Antropologia pela Universidade Federal do Amazonas (UFAM) e pesquisador do Núcleo de Estudos da Amazônica Indígena (NEAI).

Gilton Mendes dos Santos é professor do Departamento de Antropologia da UFAM e pesquisador do NEAI.

\section{REFERÊNCIAS BIBLIOGRÁFICAS}

CARNEIRO DA CUNHA, Manuela

2010 "'Cultura' e cultura: conhecimentos tradicionais e direitos intelectuais".

In Cultura com aspas e outros ensaios. Cosac \& Naify, pp. 311-373.

LATOUR, Bruno

1994 [1991] Jamais fomos modernos: ensaio de antropologia simétrica. São Paulo, Editora 34.

LIMA BARRETO, João Paulo e MENDES DOS SANTOS, Gilton

2015 "Des Poissons et des hommes - Pour une autre anthropologie". Les Temps Modernes, n. 686: 158-173.

LIMA BARRETO, João Paulo

2013 Wai-mahsã: peixes e humanos-um ensaio de antropologia indígena. Manaus, dissertação, UFAM.

MENDES DOS SANTOS, Gilton e DIAS JUNIOR, Carlos Machado 2009 "Ciência da floresta: por uma antropologia no plural, simétrica e cruzada". Revista de Antropologia (USP), v. 52, n.1: 137-160.

RAMOS, Alcida

2014 "Mentes indígenas y ecúmene antropológico". In BETRISEY, Debora e MERENSON, Silvina (Orgs). Antropologías contemporáneasSaberes, ejercícios y reflexiones. Argentina, Miño y Davila Editores. 
VIVEIROS DE CASTRO, Eduardo

1996 "Os pronomes cosmológicos e o perspectivismo ameríndio". Mana, vol. 2, n.2:114-144.

2010 Metafísicas canibales. Buenos Aires, Katz Editores.

The Return of the Anaconda-Canoe: In the Search for an Indigenous Anthropology

ABSTRACT

This text, written in four hands, deals with the process of Politicas Afirmativas in the Postgraduate Program in Anthropology of Universidade Federal do Amazonas (UFAM). It describes the confrontation of the challenges and the development of an exercise of reflexivity in the search for an indigenous anthropology
KEYWORDS

Affirmative Actions; Indigenous reflexivity; Indigenous anthropology

Recebido em 24.02.2016. Aceito em 16.03.2017. 